Journal of Economics and Behavioral Studies

Vol. 6, No. 12, pp. 947-957, December 2014 (ISSN: 2220-6140)

\title{
Factors Affecting the Improvement of Service Quality at Universities of Technology: The Case of South Africa
}

\author{
*Paul Green, OluwoleAdekanmbi \\ Durban University of Technology, South Africa \\ *paulg@dut.ac.za
}

\begin{abstract}
Several research studies have been conducted on the evaluation of service quality at conventional universities. However, this study focuses on universities of technology which are fast growing value-based educational institutions in South Africa. The uniqueness of this study highlights the issues that can affect the improvement of service at universities of technology. Three factors namely: Organizational issues, Educational issues and Staff \&Student issues were extracted as the main foci in the improvement of service at universities of technology. A mixed method methodology and an action research approach were employed in this study. The results obtained using factor analysis provides a basis for driving an equation system for evaluating the impact of the issues with respect to the factors named above. The results also show that some extraneous factors that are external to service delivery, have a substantial effect on the quality of service at universities of technology.
\end{abstract}

Keywords: Service quality, customer service, factor analysis, universities of technology, South Africa

\section{Introduction}

Academic literature is replete with information on service quality and measurement of service quality in higher education. In addition, the application of SERVQUAL as a measuring tool has been used extensively in determining the gap between perceptions and expectations of service quality in various contexts (Sultan and Wong, 2013). However, there still remains a keen interest for universities in rendering quality service and attracting and maintaining students (Shaari, 2014; Kim-Soon, Rahman \& Ahmed, 2014).Donaldson and McNicholas (2004) assert than when students are required to make an uncertain and high-risk decision in choosing a university, the student considers evidence of service quality. This assertion highlights the importance of service quality in a university context. Service quality of a university is generally evaluated by using student perception (Sumaedi, Bakti \& Metasari, 2012). The basis for this argument is that students are considered the main customers of universities (ISO, 2007; Sakthivel, Rajendran\& Raju, 2005). Despite a considerable amount of literature indicating research of service quality undertaken at universities in developed countries, e.g. USA (Ham \& Hayduk, 2003; Joseph, Yakhou, \& Stone, 2005), United Kingdom (Russel, 2005; Oldfied \& Baron, 2000) Canada (Le Blanc and Nguyen, 1997) and Australia (Soutar and McNeil, 1996) there still remains a need to conduct research in a developing country and more specifically at a university of technology. This study focuses on a university of technology in South Africa that has a main campus (Campus X) and a satellite campus (Campus Y).

As a result of changes to the educational landscape of South Africa, universities of technology were introduced during the last decade. In October 2003, the Minister of Education announced that all technikons in South Africa would henceforth be known as universities of technology. A University of Technology (UOT) is defined by du Pré (2009) as: "it is not the use of technology within a university which classifies it as a technological university, but rather the interweaving, focus and interrelation between technology and the nature of a university which constitutes a technological university." The mission of a UOT addresses the scholarship of technology from a viewpoint of diverse fields of study, as opposed to a precise field of study. Institutions of higher education regard meeting students' expectations and needs as pivotal to their success and this is no exception to UOTs. To remain competitive, as pointed out by Boyd, Walker \& Larreche (1998), a market pioneer has to perform research on the strategic thrust areas, and at a UOT, service quality is a thrust area, hence the importance of the study. This paper shows the factor analysis of issues that can affect the improvement of service at universities of technology. The paper is arranged as follows. The next section 
provides the problem statement with the aim and objectives of the study followed by a review of current literature. This is followed by the methodology and analysis in which descriptive statistics and factor analysis are presented. The final part of the paper provides a conclusion, recommendations, limitations of the study and directions for future research.

Problem Statement: Kayastha (2011) advocates that every university needs to comprehend its internal strength and weakness, and external opportunities and threats. Students enter universities with certain expectations of service quality. If these expectations are not satisfied then students will consider other universities as the whole world operates as a solitary market and universities compete for fee paying students entering the market. As asserted by Berry (1995), service is one of the distinct factors enhancing value, which can positively influence the success of a university. Over the past decade, academic literature has demonstrated how tertiary institutions have concentrated particularly on service quality as a vehicle to attract and retain students. However, the challenge remains as to which factors of service quality should managers of tertiary institutions consider and implement. To this end, this study attempts to:

Main aim: Investigate factors that influence the improvement of service quality at a university of technology.

Research Objectives: Using factor analysis to determine influential factors considered for the improvement of service quality at a university of technology.

\section{Literature Review}

The theoretical framework underpinning this research is service quality. The concept of service quality has garnered international attention mainly due to difficulty in providing a universally accepted definition and measurement. Academic literature indicates a variety of different definitions of service quality. However, a common definition of service quality is the degree to which a service meets customers' needs or expectations (Dotchin and Oakland, 1994; Asubonteng, McCleary, and Swan 1996). Service quality can therefore be understood as the difference between customer expectations of service and perceived service. In the event of a greater degree of expectation versus that of performance, then the perceived quality is less than satisfactory and hence customer dissatisfaction occurs (Parasuraman, 2004; Lewis and Mitchell, 1990). Bisschoff and Bisschoff (2001) identified customer service as a strategic thrust to gain and to retain their student numbers due to strong competition in the tertiary education market in South Africa. Potluri and Zeleke (2009) are in support of this belief by stating that service quality is the solution in the operations of higher learning institutions to the drastic changes especially in financial assistance and the negative growth in student numbers. Direct relationships between customer satisfaction and profitability have not yet been determined by conclusive research; however, researchers have indicated that a positive correlation exists between service quality through customer retention and the success of an enterprise (Ibrahim, Wang, Hassan, 2013).

This correlation is influenced by the level of service quality that customers experience. The relationship between customer service, service quality and intentions to enter into business transactions by means of an expectancy model of behaviour is where service performance forms the basis of continued business intentions of customers towards a specific enterprise. The implication of this is that a satisfied customer is the source of all profits. In the context of a university, a satisfied student becomes active in the so-called word-of-mouth promotions of the university which prove to be valuable assets to the university. A generic model designed to explain customer satisfaction is the so-called "confirmation/disconfirmation" paradigm (Davis and Heineke, 1998; Woodruff, Clemons, Schumann, Gardial and Bruns, 1991). This model shows that satisfaction or dissatisfaction is determined by the disparity between the customers' expectations (E) of a particular product or service and their perceptions of the actual performance $(\mathrm{P})$ of this product or service. In the event of customers' expectations being met, the result is that of satisfaction. Conversely, if the opposite occurs, the result is dissatisfaction occurs. Customers' satisfaction (S) can therefore be mathematically expressed as:

$$
S=E-P
$$

In addition to the variables(S, E, and P) noted above, there is a third variable, importance (I) (Szymanski and Henard, 2001; Vavra, 1997; and Matzler and Bailom, 2002 all cited in Kanning \& Bergmann, 2009). The relevance of this variable is based on the assumption that not all attributes are justifiably important to 
customers, for example, a student at university would rate academic success as being of greater importance to satisfaction as opposed to friendliness and approachability of staff. If the variable of importance is included to the model then mathematically it would be expressed as:

$$
S=(E-P) \times I
$$

The two models explicated above are deemed credible, however, according to Kanning and Bergmann (2009:378), both present conceptual problems.

Parasuraman et al. (1985) advocate that the SERVQUAL model which was founded on the GAPS model was designed to measure service quality as perceived by the customer and was developed as a result of insights obtained from interviews with executives and focus groups from selected services. The definitions of the five factors of service quality are:

Tangibles: Appearance of physical facilities, equipment, personnel and communication.

Reliability: Ability to perform the promised service dependably and accurately.

Responsiveness: Willingness to help customers and provide prompt service.

Assurance: Knowledge and courtesy of employees and their ability to convey trust and confidence.

Empathy: Caring, individualised attention the organisation provides its customers.

A study undertaken by du Toit (2004) at a South African university had as a primary objective to investigate student perceptions of service quality at the Rand Afrikaans University (RAU). The SERVQUAL model/instrument, originally developed by Parasuraman, Zeithaml and Berry (1985) was adopted. Du Toit (2004) evaluated the research undertaken in the area of service quality and selected 89 items for inclusion in the questionnaire. From the 89 selected items the following groupings were formed: Academic Services: Degree (programme), Assessment, Lecturers and Outcomes; Academic support services: Library, Computer Laboratories, Learning Centre and the Student Services Bureau; Non-Academic services: Administration, Environment, Social climate and financial aid. The study provided the following results and recommendations:

- Materials used in the promotion of the university correctly explain the degree programme.

- There is valuable feedback provided on assessments

- It was reported that questions, suggestions and objectives during lectures were appropriately handled by academics

- Disagreements regarding examination outcomes were amicable resolved.

- Time was used optimally for the delivery of each course.

- Prompt feedback was provided.

- Materials were consistently ordered in a methodical and understandable manner.

- Academics maintained discipline during lectures and developed the capacity for ingenuity and innovation.

- The learning material provided was useful and there was alignment between theory and practice.

- Lecturers were found to be approachable, helpful and well prepared for lectures.

- Lectures received favourable ratings for punctuality, fluency in the language of instruction and accessibility.

- The staffs within the faculty administration office were easily contactable, friendly and helpful.

\section{Research Design}

A mixed method methodology and action research was employed in this study. A sampling technique known as purposive convenience sampling was used as participants were selected for the study. The empirical work undertaken in the study involved a total of 50 participants who were senior members of a UOT and experts in the field of quality assurance. Participants were drawn from academic and administrative staff from the university. Workshops were conducted across two campuses of the university. The responses were collected from a questionnaire comprising of pair wise comparison between the factors that constitute the objectives. The responses were confirmed and authenticated by a follow up with some interviews and meetings with the senior members of the university. The study demanded that the participants be allowed to openly express their views and opinions. The aim of the workshops was to determine the factors for the improvement of service quality at universities of technology. The responses were capturedusing the SPSS package (Version 21). 
Derivation of issues related to service quality evaluation - A brainstorming technique was utilized by the participants of the workshop to generate ideas on improving quality of service at universities of technology. These ideas were documented using a flip chart approach. The following illustrates the issues raised by the participants of the workshops:

Staff to exercise courtesy and responsive approach towards students.

University requires a contextual evaluation system.

An awareness made by students on the co-production of service delivery. Students to realise

that service is co-produced.

Skills' training is required in order to develop effective customer service across the entire university.

The new general education modules at the university should incorporate content on customer service and service delivery.

There are inconsistencies in the rendering of service quality across the university.

There seems to be a lack of ownership in assuring and evaluating service quality holistically.

Chain of command is not well-defined hence staffs feel answerable to many managers.

All evaluation practices and performance management tools should incorporate elements of service quality of the institution as a whole.

Develop and nurture an organisational culture of efficient and effective service.

These issues regarded as factors comprise the pathways through which service quality can be improved and can help to improve service delivery at universities of technology. Ten key issues were categorized into three areas: Organisational factors, Educational factors, and Staff and Student factors. The categorization of the factors is presented in Table 1.

\section{Table 1: Categorization of Identified Factors}

\begin{tabular}{lll}
\hline No & Factors & Sub-Factors \\
\hline 1 & Organizational Factors & SF02: University requires a contextual evaluation system. \\
& SF06: There are inconsistencies in the rendering of service quality \\
& across the university. \\
& SF07: There seems to be a lack of ownership in assuring and \\
& evaluating service quality holistically. \\
& SF09: All evaluation practices and performance management tools \\
& should incorporate elements of service quality of the institution as a \\
& whole. \\
& SF10: Develop and nurture an organizational culture of efficient and \\
& effective service. \\
& SF04: Skills' training is required in order to develop effective \\
& customer service across the entire university. \\
& SF05: The new general education modules at the university should \\
& incorporate content on customer service and service delivery. \\
& SF03: An awareness made by students on the co-production of \\
& Service delivery. Students to realise that service is co-produced. \\
& SF08: Chain of command is not well-defined hence staffs feel \\
& answerable to many managers. \\
& SF01: Staff to exercise courtesy and responsive approach towards \\
& students. \\
\hline
\end{tabular}

\section{Analysis and Results}

A seven-point scaling technique was used for gathering data. The scaling technique measures the ratios of intensities of the importance of the factors. The scaling technique has values ranging from $0-10$ depending on the degree of importance where $0=$ no importance, $5=$ low importance, $6=$ moderate importance, $7=$ equal 
importance, 8 = strong importance, $9=$ absolute importance, and $10=$ extreme importance. The following statistics were used for the purpose of achieving the above stated goal.

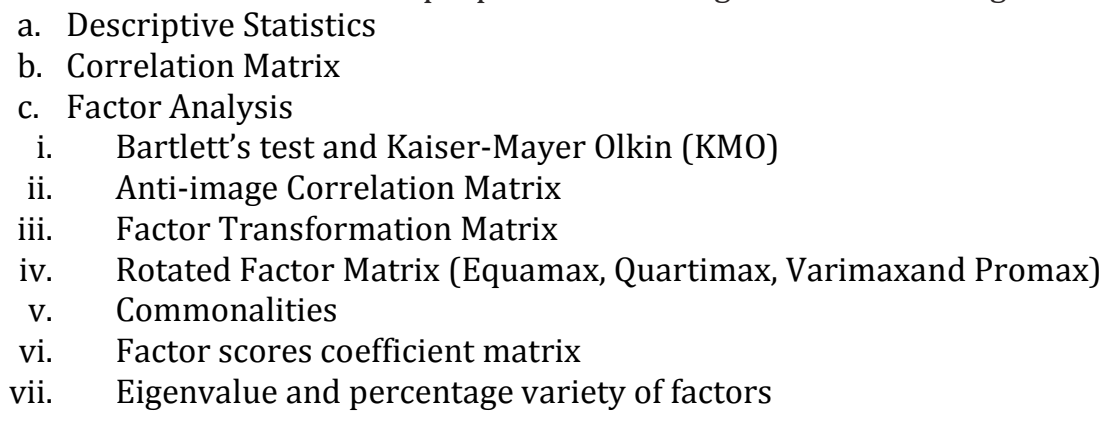

Descriptive Statistics: Descriptive statistics were used for obtaining the mean and standard deviation of the value of each decision variable. The result of the descriptive statistics based upon the comparison scaling technique states that most of the issues or sub-factors are important for the improvement of service quality in universities of technology. For example, the factor 'organizational issues' has five sub-factors, the mean scores of the sub-factors 2, sub-factors 6, sub-factors 7, sub-factors 9 and sub-factors 10 at Campus X and Campus Y are between 6.47 and 9.2 suggesting that these sub-factors fall between moderate importance and absolute importance. The standard deviations of these sub-factors are between 0.577 and 1.181. The factor 'educational issues' has two sub-factors, the mean scores of the sub-factors 4 and sub-factors 5 at Campus X and Campus $\mathrm{Y}$ are between 6.6 and 8.31 signifying that the sub-factors have strong importance and are equally important to the rest of the sub-factors. The standard deviations of these sub-factors are between 0.617 and 0.828 . The factor 'staff \& student issues' has three sub-factors, the mean scores of the sub-factors 1 , sub-factors 3 and sub-factors 8 at Campus $X$ and Campus $Y$ are between 6.33 and 8.4. The standard deviations of these sub-factors are between 0.704 and 1.113. Detailed descriptive statistics of the data collected are presented in Table 2, which also exhibits the mean and standard deviation of the rating of the impact of the sub-factors for the improvement of service quality at universities by the respondents.

Table 2: Descriptive Statistics

\begin{tabular}{ll}
\hline \multicolumn{1}{c}{$\begin{array}{c}\text { Campus X } \\
\text { Mean (Std. Dev.) }\end{array}$} & $\begin{array}{l}\text { Campus Y } \\
\text { Mean (Std. Dev.) }\end{array}$ \\
\hline SF017.93 (.961) & $8.81(.911)$ \\
SF029.20 (.775) & $7.94(1.181)$ \\
SF038.40 (.828) & $6.69(.704)$ \\
SF047.67 (.617) & $8.31(.704)$ \\
SF056.60 (.828) & $6.63(.719)$ \\
SF066.47 (1.060) & $7.19(.750)$ \\
SF077.87 (.990) & $7.50(1.155)$ \\
SF086.33 (1.113) & $7.00(1.033)$ \\
SF096.60 (1.056) & $7.75(.577)$ \\
SF109.13 (.743) & $9.00(.816)$ \\
\hline
\end{tabular}

Correlation Matrix: The correlation matrix presents the strength and direction of the association between two scales or ordinal decision variables. The correlation matrix of the impact indices was generated for Campus $\mathrm{X}$ and Campus $\mathrm{Y}$ respondents are presented in Table 3 and Table 4 respectively. In Table 3, the analysis of the correlation matrix shows that the highest correlation of 0.574 exists between the Sub-Factor 2 and Sub-Factor 6. The least correlation of -0.77 exists between Sub-Factor 1 and Sub-Factor 2. The implication is that Sub-Factor 2 is very likely to have the same impact as Sub-Factor 6. On the other hand, Sub-Factor 1 is not likely to have the same impact as Sub-Factor 2. This conforms to the grouping of the factors where Sub-Factor 2 and Sub-Factor 6 are grouped under organizational issues while Sub-Factor 1 falls under staff\& students' issues. 
Table 3: Correlation Matrix for Campus X

\begin{tabular}{lllllllllll}
\hline & SF01 & SF02 & SF03 & SF04 & SF05 & SF06 & SF07 & SF08 & SF09 & SF10 \\
\hline SF01 & 1.00 & -.077 & .215 & -.281 & .144 & .313 & -.010 & .022 & .183 & .213 \\
SF02 & -.077 & 1.00 & -.022 & .299 & .022 & $.574^{*}$ & -.242 & .166 & -.507 & .447 \\
SF03 & .215 & -.022 & 1.00 & .140 & .042 & .260 & -.105 & .310 & -.294 & .023 \\
SF04 & -.281 & .299 & .140 & 1.00 & -.419 & -.182 & .273 & -.347 & -.110 & .104 \\
SF05 & .144 & .022 & .042 & -.419 & 1.00 & -.016 & -.157 & -.078 & -.360 & -.371 \\
SF06 & .313 & $.574^{*}$ & .260 & -.182 & -.016 & 1.00 & -.413 & .464 & -.332 & $.550^{*}$ \\
SF07 & -.010 & -.242 & -.105 & .273 & -.157 & -.413 & 1.00 & $-.670^{* *}$ & .287 & -.071 \\
SF08 & .022 & .166 & .310 & -.347 & -.078 & .464 & $-.670^{* *}$ & 1.00 & -.243 & .202 \\
SF09 & .183 & -.507 & -.294 & -.110 & -.360 & -.332 & .287 & -.243 & 1.00 & -.291 \\
SF10 & .213 & .447 & .023 & .104 & -.371 & $.550^{*}$ & -.071 & .202 & -.291 & 1.00 \\
\hline
\end{tabular}

*. Correlation is significant at the 0.05 level (2-tailed).

**. Correlation is significant at the 0.01 level (2-tailed).

Table 4: Correlation Matrix for Campus Y

\begin{tabular}{lllllllllll}
\hline & SF01 & SF02 & SF03 & SF04 & SF05 & SF06 & SF07 & SF08 & SF09 & SF10 \\
\hline SF01 & 1.00 & -.074 & $-.513^{*}$ & .097 & .089 & .055 & .159 & .000 & .412 & -.090 \\
SF02 & -.074 & 1.00 & .055 & -.295 & .128 & .240 & .415 & -.164 & .171 & .138 \\
SF03 & $-.513^{*}$ & .055 & 1.00 & -.193 & .016 & -.260 & -.041 & .092 & -.369 & .464 \\
SF04 & .097 & -.295 & -.193 & 1.00 & .115 & -.245 & -.123 & .183 & .041 & -.232 \\
SF05 & .089 & .128 & .016 & .115 & 1.00 & .263 & $.562^{*}$ & $-.539^{*}$ & .241 & .341 \\
SF06 & .055 & .240 & -.260 & -.245 & .263 & 1.00 & .269 & -.430 & .115 & .109 \\
SF07 & .159 & .415 & -.041 & -.123 & $.562^{*}$ & .269 & 1.00 & -.056 & .100 & .000 \\
SF08 & .000 & -.164 & .092 & .183 & $-.539^{*}$ & -.430 & -.056 & 1.00 & .224 & -.395 \\
SF09 & .412 & .171 & -.369 & .041 & .241 & .115 & .100 & .224 & 1.00 & .000 \\
SF10 & -.090 & .138 & .464 & -.232 & .341 & .109 & .000 & -.395 & .000 & 1.00 \\
\hline
\end{tabular}

*. Correlation is significant at the 0.05 level (2-tailed).

**. Correlation is significant at the 0.01 level (2-tailed).

Factor Analysis: Following the work of de Winter, Dodou and Wieringa (2009) who advocate that factor analysis can yield good results for small sample sizes whereby the reasonable absolute minimum number should be a sample size of 50 , the sample size used in this study was 50 . The factor analysis of principal components was applied for the assessment of the effects of issues for the improvement of service quality.

Table 5: Anti-image Matrices for Campus X

\begin{tabular}{|c|c|}
\hline & SF01SF02SF03 SF04SF05SF06SF07SF08SF09SF10 \\
\hline \multirow{10}{*}{ Anti-image Correlation } & 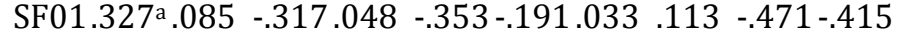 \\
\hline & 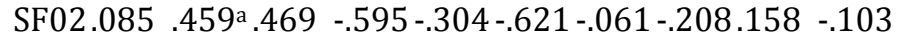 \\
\hline & SF03-.317.469 .221a -.505-.106-.400-.260 -.439.318.242 \\
\hline & SF04.048 -.595 -.505.286a .604 . 119. 1932. 155 \\
\hline & 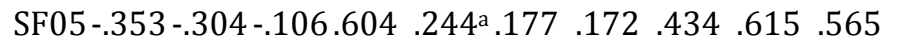 \\
\hline & 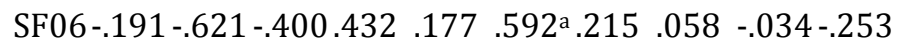 \\
\hline & SF07.033 -.061 -.260.155. 172 $215.612^{\text {a }} .599-069-. .137$ \\
\hline & 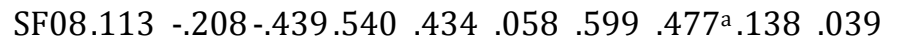 \\
\hline & SF09-.471.158 318. 193. 615 -.034-.069.138.444a \\
\hline & SF10-.415-.103.242 $119.565-.253-.137 .039$.532 $\quad .468^{a}$ \\
\hline
\end{tabular}

a. Measures of Sampling Adequacy(MSA)

The anti-image correlation matrix contains the negatives of the partial correlation coefficients, which is another form of a matrix that describes the linear relationship between two variables while controlling for the effects of one or more additional decision variables. The anti-image correlation matrix generated for Campus $\mathrm{X}$ and Campus $\mathrm{Y}$ respondents are presented in Table 5 and Table 6 respectively. In Table 5, the analysis of the anti-image correlation matrix shows that Sub-Factor 7 namely 'Lack of ownership in assuring 
and evaluating service quality holistically' has the highest measure of sampling accuracy of 0.612 while Table 6 shows that Sub-Factor 10 namely 'Develop and nurture an organizational culture of efficient and effective service' has the highest measure of sampling accuracy of 0.553 .

Table 6: Anti-image Matrices for Campus Y

\begin{tabular}{|c|c|}
\hline & SSF01SF02SF03SF04SF05SF06SF07SF08SF09SF10 \\
\hline \multirow{10}{*}{ Anti-image Correlation } & 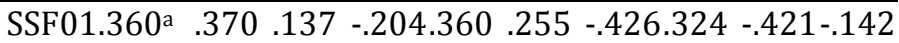 \\
\hline & $\begin{array}{lllll}\text { SF02 } & .370 & .158^{a}-.390-.304 .657 .059 .053 & -.722 .641 & -180\end{array}$ \\
\hline & 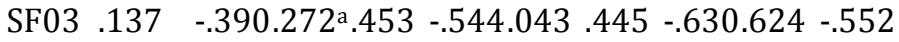 \\
\hline & $\begin{array}{llll}\text { SF04 } & -.204 & -.304 .453 .153^{a}-.652-.029 .572 & -.591 .532 \\
\end{array}$ \\
\hline & 年 $657-.544-.652 .195^{\mathrm{a}} .280-.896 .892-.834 .049$ \\
\hline & إ. \\
\hline & 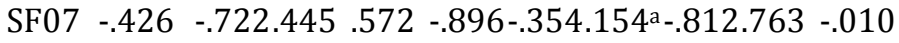 \\
\hline & .641 -.630-.591.892 .389 -.812.170a -.861.284 \\
\hline & 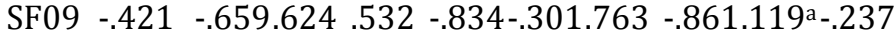 \\
\hline & $52.000 .049-.031-.010 .284-.2$ \\
\hline
\end{tabular}

a. Measures of Sampling Adequacy(MSA)

The Kaiser-Meyer-Olkin (KMO) measure of sampling adequacy tests whether the partial correlations among variables are small. Bartlett's test of sphericity tests whether the correlation matrix is an identity matrix, which would indicate that the factor model is inappropriate. The Bartlett's test for Campus X respondents produces a $\chi^{2}$ of 49.127, degree of freedom of 45 and a significance level of 0.0311 , while that of Campus $Y$ respondents produces a $\chi^{2}$ of 51.978, degree of freedom of 45 and a significance level of 0.0221 , which shows that the sample population is adequate. High values (close to 1.0) for a measure of sampling accuracy generally indicate that a factor analysis may be useful with your data. If the value is less than 0.50 , the results of the factor analysis probably will not be very useful. The KMO test for both Campus X and Campus $\mathrm{Y}$ respondents produce a measure of 0.758 and 0.709 respectively, which further confirms that the sample population is adequate.

Table 7: Communalities

\begin{tabular}{lll}
\hline & $\begin{array}{l}\text { Campus } \\
\text { Extraction }\end{array}$ & $\begin{array}{c}\text { X Campus Y } \\
\text { Extraction }\end{array}$ \\
\hline SF01 & .536 & .558 \\
SF02 & .714 & .675 \\
SF03 & .136 & .708 \\
SF04 & .750 & .533 \\
SF05 & .688 & .746 \\
SF06 & .788 & .430 \\
SF07 & .583 & .505 \\
SF08 & .593 & .719 \\
SF09 & .779 & .481 \\
SF10 & .737 & .549 \\
\hline
\end{tabular}

Table 8: Initial factor Matrix

\begin{tabular}{lllllll}
\hline & \multicolumn{3}{c}{ Campus X } & \multicolumn{5}{c}{ Campus Y } \\
Factor & $\mathbf{1}$ \\
& $\mathbf{1}$ & $\mathbf{2}$ & $\mathbf{3}$ & $\mathbf{1}$ & $\mathbf{2}$ & $\mathbf{3}$ \\
\hline SF01 & .193 & -.327 & .626 & .133 & .728 & -.102 \\
SF02 & .645 & .486 & -.249 & .537 & -.070 & .618 \\
SF03 & .362 & -.066 & .010 & -.050 & -.837 & .078 \\
SF04 & -.149 & .833 & -.187 & -.336 & .346 & -.548 \\
SF05 & .084 & -.609 & -.556 & .753 & .078 & -.416 \\
SF06 & .849 & .042 & .257 & .639 & .138 & .050 \\
SF07 & -.655 & .366 & .141 & .626 & .187 & .280 \\
SF08 & .697 & -.311 & .100 & -.670 & .207 & .476 \\
SF09 & -.621 & -.148 & .610 & .212 & .632 & .192 \\
SF10 & .573 & .484 & .416 & .471 & -.518 & -.243 \\
\hline
\end{tabular}

In factor analysis, the proportion of the variance of a variable explained by the common sub-factor is called the 'commonality' of the variable. The commonalities shown in Table 7 ranges between 0 and 1 , where 0 indicates that the common sub-factor accounts for none of the variance and 1 indicates that all the variance can be accounted for by the common sub-factor. For instance, in Campus X, sub-factor 9 'All evaluation practices and performance management tools should incorporate elements of service quality of the institution as a whole' has the highest commonality value of 0.779 suggesting that $77.9 \%$ of the variance can be accounted for by the extracted factor. In contrast, lower commonality values are obtained for variables such as 'Staff to exercise courtesy and responsive approach towards students' (0.536, sub-factor 1$)$, 'There 
seems to be a lack of ownership in assuring and evaluating service quality holistically' (0.583, sub-factor 7), 'Chain of command is not well-defined hence staff feel answerable to many managers' (0.593, sub-factor 8). The lowest communality value was produced by sub factor 3 -'An awareness made by students on the coproduction of service delivery. Students to realize that service is co-produced' with a value of 0.136 . In Campus Y, sub-factor 5 'The new general education modules at the university should incorporate content on customer service and service delivery' has the highest commonality value of 0.746 . Lower communality values were produced by variables such as 'Skills' training is required in order to develop effective customer service across the entire university' (0.533, sub-factor 4$)$, 'Develop and nurture an organizational culture of efficient and effective service' $(0.549$, sub-factor 10$)$. Sub-factor 6 - 'There are inconsistencies in the rendering of service quality across the university' produced the lowest communality value of 0.430 . The remaining $46.4 \%$ (Campus $\mathrm{X}$ - sub factor 1 ) and $44.2 \%$ (Campus $\mathrm{Y}$ - sub factor 1 ) can be attributed to other factors, which are irrelevant to improving service quality. The factor matrix presents the initial factor loading. The degree of generalization found between each variable and each factor is referred to as 'Factor Loading'. The farther a factor loading is from zero in the positive direction, the more one can conclude the contribution of a variable to a factor. The factor matrix can be rotated by equamax (combination of the varimax and quartimax), quartimax (which simplifies the variables), varimax (which simplifies the factors), and promax (which allows factors to be correlated) for the purpose of establishing a higher correlation between variables and factors. In order to obtain a meaningful factor loading, the principal component matrixwas tested by rotating the matrix by equamax, quartimax, promax, and varimax. Of all the orthogonal rotation method, Quartimax with Kaiser Normalization produced the best result by converging in the $4^{\text {th }}$ iteration. As a result, Quartimax rotation method is employed for the purpose of this analysis. The factor transformation, rotated factor matrix, and factor score coefficient matrix are presented in Table 9, Table 10 and Table 11 respectively. In Campus X, the factor 1 has the highest correlation of the value 0.979 in the matrix while in Campus Y, factor 2 with factor 1 have the highest correlation of the value 0.988 in the matrix.

Table 9: Factor Transformation Matrix

\begin{tabular}{lllllll}
\multicolumn{2}{l}{ Campus X } & \multicolumn{5}{c}{ Campus Y } \\
Factor & $\mathbf{1}$ & $\mathbf{2}$ & $\mathbf{3}$ & $\mathbf{1}$ & $\mathbf{2}$ & $\mathbf{3}$ \\
\hline 1 & .979 & .140 & -.147 & .156 & .805 & .572 \\
2 & -.201 & .778 & -.596 & .988 & -.123 & -.097 \\
3 & .031 & .613 & .789 & .008 & -.580 & .815 \\
\hline
\end{tabular}

Table 10: Rotated Factor Matrix

\begin{tabular}{lllllll}
\hline \multicolumn{3}{c}{$\begin{array}{l}\text { Campus X } \\
\text { Factor }\end{array}$} & \multicolumn{5}{c}{ Campus $\mathbf{~}$} \\
& $\mathbf{1}$ & $\mathbf{2}$ & $\mathbf{3}$ & $\mathbf{1}$ & $\mathbf{2}$ & $\mathbf{3}$ \\
\hline SF01 & .274 & .157 & .660 & .739 & .076 & -.078 \\
SF02 & .526 & .315 & -.581 & .020 & .082 & .817 \\
SF03 & .368 & .006 & -.006 & -.833 & .018 & .116 \\
SF04 & -.319 & .512 & -.622 & .285 & .004 & -.672 \\
SF05 & .187 & -.803 & -.089 & .192 & .838 & .084 \\
SF06 & .831 & .309 & .053 & .236 & .469 & .392 \\
SF07 & -.710 & .279 & -.010 & .285 & .319 & .568 \\
SF08 & .748 & -.083 & .161 & .103 & -.841 & -.015 \\
SF09 & -.559 & .172 & .661 & .659 & -.018 & .216 \\
SF10 & .477 & .712 & -.044 & -.440 & .583 & .122 \\
\hline
\end{tabular}

Table 11: Factor Score Coefficient Matrix

\begin{tabular}{lllllll}
\hline \multicolumn{3}{c}{$\begin{array}{l}\text { Campus X } \\
\text { Factor }\end{array}$} & \multicolumn{5}{c}{$\begin{array}{l}\text { Campus } \\
\text { Factor }\end{array}$} \\
& $\mathbf{1}$ & $\mathbf{2}$ & $\mathbf{3}$ & $\mathbf{1}$ & $\mathbf{2}$ & $\mathbf{3}$ \\
\hline SF01 & .112 & .142 & .436 & .346 & .047 & -.068 \\
SF02 & .156 & .123 & -.321 & .005 & -.105 & .521 \\
SF03 & .127 & -.006 & .008 & -.391 & -.003 & .077 \\
SF04 & -.141 & .254 & -.356 & .136 & .121 & -.443 \\
SF05 & .080 & -.482 & -.118 & .081 & .427 & -.097 \\
SF06 & .282 & .167 & .085 & .104 & .175 & .171 \\
SF07 & -.252 & .179 & -.005 & .128 & .063 & .313 \\
SF08 & .265 & -.052 & .118 & .057 & -.444 & .142 \\
SF09 & -.176 & .170 & .412 & .308 & -.055 & .142 \\
SF10 & .147 & .403 & .048 & -.213 & .292 & -.024 \\
\hline
\end{tabular}

The factor score coefficient matrix presented in Table 11 can be used to assess the impact of the factors for the improvement of service quality. The assessment can be realized by formulating a linear equation in the form:

$$
I_{i, k}=\sum_{i=1}^{10} \sum_{j=1}^{10} \sum_{k=1}^{3} S_{i, j} F_{j, k}
$$


Where $I_{i, k}$ is the impact of $i^{\text {th }}$ assessor to $k^{\text {thfactor, }} F_{j, k}$ is the factor score coefficient of $j^{\text {th }}$ decision variable for $k^{\text {th }}$ factor, and $S_{i, j}$ is the value of the $i^{\text {th }}$ assessor for $j^{\text {th }}$ decision variable. In order to evaluate the impact percentage of each factor to the total impact, the eigenvalue of each factor is calculated. The eigenvalue of $k^{\text {th }}$ factor $\left(E_{k}\right)$ is the summation of the loading of $k^{\text {th }}$ factor on $j^{\text {th }}$ decision variable denoted by $x_{i, k}$. The eigenvalue of $k^{\text {th }}$ factor can be expressed as follows:

$$
E_{k}=\sum_{j=1}^{10} \sum_{k=1}^{3} x_{j, k}
$$

The eigenvalue is used to indicate the proportion of variance explained by each of the dimensions in the responses. The impact percentage (IP) of each factor is defined by:

$$
\mathrm{IP}=100 *\left(\frac{\text { eigenvalue of factor }}{\text { number of decision variable }}\right)
$$

Table 12shows the eigenvalue, impact percentage and cumulative impact percentage of the extracted three factors.

\begin{tabular}{|c|c|c|c|c|c|c|}
\hline \multirow[b]{2}{*}{ Factor } & \multicolumn{2}{|c|}{$\begin{array}{l}\text { Campus X } \\
\text { Extraction } \\
\text { Loadings }\end{array}$} & $S$ of Squ & $\begin{array}{l}\text { Camp } \\
\text { dExtrac } \\
\text { Loadi }\end{array}$ & \multicolumn{2}{|c|}{ Sums of Squared } \\
\hline & Total & $\begin{array}{l}\text { \% } \\
\text { Variance }\end{array}$ & $\begin{array}{l}\text { ofCumulative } \\
\%\end{array}$ & Total & $\begin{array}{l}\% \\
\text { Variance }\end{array}$ & $\begin{array}{l}\text { ofCumulative } \\
\%\end{array}$ \\
\hline 1 & 2.505 & 25.047 & 25.047 & 2.963 & 29.630 & 29.630 \\
\hline 2 & 2.125 & 21.252 & 46.300 & 1.900 & 19.002 & 48.633 \\
\hline$\underline{3}$ & 1.275 & 12.752 & 59.052 & 1.440 & 14.400 & 63.033 \\
\hline
\end{tabular}

Table 12: Eigenvalues and Percentage Variance

The impact of the first factor which is described as 'Organizational Issue' is $25.047 \%$ out of the $59.052 \%$, which translates to $42.4151 \%$ for Campus $\mathrm{X}$ and $29.630 \%$ out of the $63.033 \%$ which translates to $47.0071 \%$. The results indicate that the factor does have an impact on the improvement of service quality. The second factor which is described as 'Educational Issues' contributes $46.300 \%$ out of the $59.052 \%$, which translates to $78.4054 \%$ for Campus X and $48.633 \%$ out of the $63.033 \%$ which translate to $77.1548 \%$ for Campus Y. The results indicate that the factor has a tremendous impact on the improvement of service quality. Thus the third factor which is described as 'Staff and Students Issues' contributes $59.052 \%$ to the overall impact for Campus $\mathrm{X}$ and $63.033 \%$ to the overall impact for Campus Y. The remaining $40.948 \%$ inCampus $\mathrm{X}$ and $36.967 \%$ in Campus $\mathrm{Y}$ are considered to be the impact of some extraneous factors, for example union strikes and infrastructure.

\section{Conclusion and recommendations}

This paper has illustrated the application of the principal component method of extraction in factor analysis to determine factors considered to influence the improvement of the quality of service at a university. Three factors, namely: Organizational issues, Educational issues, and Staff \&Student issues were considered in this study. The results obtained by using quartimax orthogonal transformation exhibit the following features:

- The average contribution of Factor 1 to the overall impact is $44.7111 \%$.

- The average contribution of Factor 2 to the overall impact is $77.7801 \%$.

- The average contribution of Factor 3 to the overall impact is $61.0425 \%$

- Other factors external to the improvement of service quality have an average contribution of $38.9575 \%$.

The results obtained place a high demand on research related to solving educational issues at the university. Therefore, it could be concluded that Educational issues are a major factor in improving quality of service at universities of technology. This factor, in practice, determines the institution's development, staff and student productivity and mode of service delivery as a whole. It also emphasizes the importance of skills training in order to develop effective and efficient service. Managers and individuals responsible for curriculum 
development should definitely consider customer service and service delivery as a cornerstone module in improving the quality of service delivery at institutions of higher learning. This finding is consistent with other research (see Kayastha, 2011) who found that academic aspects are an important variable that positively influences satisfaction levels. The results of this study are in alignment with studies using comparable techniques. Similar studies using a large sample with the more intense criteria models would be useful in order to corroborate this study's findings and to address the limitation of the small sample size and the sample frame of one university.

\section{References}

Asubonteng, P., McCleary, K. \& Swan, J. (1996). SERVQUAL Revisited: A Critical Review of Service Quality. The Journal of Services Marketing, 10(6), 62-81.

Berry, L. L. (1995). Relationship Marketing of Services--Growing Interest, Emerging Perspectives. Journal of the Academy of Marketing Science, 23(4), 236-45.

Bisschoff, C. A. \& Bisschoff, A. (2001). Customer service factors of a Telemetric Learning BBA degree. South African Journal of Education, 21(4), 228-233.

Boyd, N., Walker, E. \& Larreche, P. (1998). Marketing Strategy. New York: Irwin.

Davis, M. M. \& Heineke, J. (1998). How disconfirmation, perception and actual waiting times impact customer satisfaction. International Journal of Service Industry Management, 9, 64- 73.

de Winter, J. C. F., Dodou, D. \& Wieringa, P. A. (2009) Exploratory Factor Analysis With Small Sample Sizes. Multivariate Behavioural Research, 44, 147-181.

Donaldson, W. G. \& McNicholas, C. (2004). Understanding the postgraduate education market for UK based students. Journal of non-profit and Voluntary Sector Marketing, 9(4), 346-360.

Dotchin, J. A. \& Oakland, J. S. (1994). Total Quality Management in Services, Part 1: Understanding and Classifying Services. International Journal of Quality \& Reliability Management, 11(3), 9-36.

Du Pré, R. (2009). The Place and Role of Universities of Technology in South Africa. Bloemfontein, South Africa: South African Technology Network.

DuToit, A. (2004). How satisfied are our Students? Proceedings of the $1^{\text {st }}$ International Conference on Teaching and Learning in Higher Education. Centre for the Development of Teaching and Learning, National University of Singapore. Singapore.

Ham, L. \& Hayduk, S. (2003). Gaining competitive advantage in higher education: analyzing the gap between expectations and perceptions of service quality. International Journal of Value-Based Management, 16(3), 223-242.

Ibrahim, E., Wang, L. \& Hassan, A. (2013). Expectations and Perceptions of Overseas Students towards Service Quality of Higher Education Institutions in Scotland. International Business Research, 6(6), 20-30.

ISO. (2007). IWA 2, Quality Management Systems - Guidelines for the application of ISO 9001:2000 in Education, ISO, Geneva.

Joseph, M., Yakhou, M. \& Stone, G. (2005). An educational institution's quest for service quality: customers' perspective. Quality Assurance in Education, 13(1), 66-82.

Kanning, U. P. \& Bergmann, N. (2009). Predictors of customer satisfaction: testing the classical paradigms. Managing Service Quality, 9(4), 377-390.

Kayastha, A. (2011). A Study of Graduate Student Satisfaction towards Service Quality of Universities in Thailand. Masters Degree in Business Administration (MBA).Webster University, Thailand.

Kim-Soon, N., Rahman, A. \& Ahmed, M. (2014). E-Service Quality in Higher Education and Frequency of Use of the Service. International Education Studies, 7(3), 1-10.

Le Blanc, G. \& Nguyen, N. (1997). Searching for excellence in business education: an exploratory study of customer impressions of service quality. International Journal of Educational Management, 11(2), 72-79.

Lewis, B. R. \& Mitchell, V. W. (1990). Defining and Measuring the Quality of Customer Service. Marketing Intelligence \& Planning, 8(6), 11-17.

Oldfield, B. M. \& Baron, S. (2000). Student perceptions of service quality in a UK university business and management faculty. Quality Assurance in Education, 8(2), 85-95.

Parasuraman, A., Zeithmal, V. A. \& Berry, L. L. (1985). A Conceptual Model Service Quality and its Implications for Future Research. Journal of Marketing, 49(4), 41-50. 
Parasuraman, A. (2004). Assessing and Improving Service Performance for Maximum Impact: Insights from a Two-Decade-Long Research Journey. Performance Measurements and Metrics, 5(2), 45-52.

Potluri, R. M. \& Zeleke, A. A. (2009). Evaluation of customer handling competencies of Ethiopian employees. African Journal of Business Management, 3(4), 131-135.

Russell, M. (2005). Marketing education: a review of service quality perceptions among international students. International Journal of Contemporary Hospitality Management, 17(1), 65-77.

Sakthivel, P. B., Rajendran, G. \& Raju, R. (2005) TQM implementation and students satisfaction of academic performance. The TQM Magazine, 17(6), 573-589.

Shaari, H. (2014). Service Quality in Malaysian Higher Education: Adult Learners' Perspective. International Journal of Business and Social Science, 5(1), 86-90.

Soutar, G. \& McNeil, M. (1996).Measuring service quality in a tertiary institution. Journal of Educational Administration, 34(1), 72-82.

Sultan, P. \& Wong, H. P. (2013). Antecents and consequences of service quality in a higher education context. Quality Assurance in Education, 21(1), 70-95.

Sumaedi, S., Bakti, G. M. Y. \& Metasri, N. (2012). An empirical study of state university students' perceived service quality. Quality Assurance in Education, 20(2), 164 -183.

Woodruff, R. B., Clemons, D. S., Schumann, D. W., Gardial, S. F. \& Bruns, M. J. (1991). The standards issue in CS/D research: A historical perspective. Journal of Customer Satisfaction Dissatisfaction and Complaining Behaviour, 4, 103-109. 